\title{
Language profiles in Autism Spectrum Disorders (ASD), Specific Language Impairment (SLI) and Attention Deficit Hyperactivity Disorder (ADHD)
}

\author{
Comentado por: Debora M. Befi-Lopes ${ }^{1}$, Ana Manhani Cáceres ${ }^{2}$
}

Geurts HM, Embrechts M. Language profiles in ASD, SLI, and ADHD. J Autism Dev Disord. 2008;38:1931-43.

A natureza das dificuldades pragmáticas e sua extensão parecem diferir entre as patologias da comunicação. $\mathrm{O}$ uso funcional da linguagem é afetado por habilidades sociais e seu déficit pode ser percebido na intenção comunicativa, nas pressuposições e no gerenciamento do discurso. Este estudo investigou o perfil comunicativo de crianças com diagnóstico de Distúrbio do Espectro Autístico (DEA), de Transtorno do Déficit de Atenção com Hiperatividade (TDAH) e de Distúrbio Específico de Linguagem (DEL), a partir de respostas dos pais a um questionário - Children's Communication Checklist-2 (CCC-2).

Os autores realizaram duas investigações no mesmo estudo que tinham como objetivos primeiramente verificar se há um perfil específico de linguagem nas crianças com DEA no que se refere à natureza, extensão e déficits das habilidades de linguagem e se estes perfis dependem da idade e, além disso, investigar como o que foi observado nestas crianças se relaciona aos perfis linguísticos em outros distúrbios como TDAH e DEL.

As crianças com DEA possuem atraso de linguagem em diversas áreas, sendo a pragmática a mais evidente delas. Pesquisas recentes indicam que os pré-escolares tendem a apresentar déficits na forma, no conteúdo e no uso da linguagem, ao passo que nos escolares os déficits pragmáticos se tornam mais evidentes.

No TDAH é frequente a observação de prejuízos na linguagem, porém a tríade de características clássicas compreende falta de atenção, hiperatividade e impulsividade. Todavia, atualmente, nota-se que estas crianças demonstram prejuízo nas habilidades pragmáticas (conversas estereotipadas, manutenção do tópico conversacional e dificuldades de relacionamento social).

O DEL é uma patologia primária que acomete o desenvolvimento linguístico, cujas dificuldades recaem principalmente nos aspectos estruturais, mas também são observados déficits

(1) Livre-docente, Professora Associada do Curso de Fonoaudiologia do Departamento de Fisioterapia, Fonoaudiologia e Terapia Ocupacional da Faculdade de Medicina da Universidade de São Paulo - USP - São Paulo (SP), Brasil.

(2) Fonoaudióloga assistente do Curso de Fonoaudiologia do Departamento de Fisioterapia, Fonoaudiologia e Terapia Ocupacional da Faculdade de Medicina da Universidade de São Paulo - USP - São Paulo (SP), Brasil.

Endereço para correspondência: Debora Maria Befi-Lopes. R. Cipotânia, 51, Cidade Universitária, São Paulo (SP), Brasil, CEP: 05360-160. E-mail: dmblopes@usp.br pragmáticos, que normalmente decorrem do déficit linguístico.

No estudo que ora apresentamos, uma primeira investigação comparou três grupos de crianças (com DEA, com TDAH e em Desenvolvimento Típico) entre sete e catorze anos. O instrumento utilizado para tal comparação foi o CCC-2, que possui dez escalas: quatro relacionadas com diferentes aspectos do uso pragmático da linguagem, quatro que avaliam os aspectos estruturais do uso da linguagem, e duas que avaliam domínios não linguísticos. Ele difere do anterior (primeira versão do CCC) por ser capaz de delinear melhor semelhanças e diferenças nos perfis linguísticos.

As crianças com DEA e as com TDAH tiveram dificuldades pragmáticas, mas apenas os pais das primeiras relataram maiores dificuldades com as habilidades sociais do que com as estruturais. O grupo com TDAH obteve resultados intermediários, sendo que os grupos clínicos diferiram para o uso do contexto, comunicação não verbal e relações sociais.

A segunda investigação verificou se o perfil das habilidades linguísticas e se as dificuldades de pré-escolares com DEA são semelhantes às de crianças autistas entre sete e catorze anos. Os resultados demonstram um padrão oposto entre as faixas etárias estudadas, ou seja, as crianças mais novas, segundo seus pais, apresentam mais dificuldades com aspectos estruturais do que com aspectos pragmáticos.

Quando comparados aos DEL, as crianças com DEA apresentam mais comprometimentos no que se refere ao número de aspectos da linguagem afetados, porém, os dois grupos apresentaram déficits na estrutura linguística e os relatos dos pais dos pré-escolares com DEL confirmaram a heterogeneidade das manifestações de linguagem apresentadas por essa população.

Assim, os pré-escolares autistas tiveram prejuízo em todas as escalas, inclusive naquelas relacionadas à forma da linguagem, o que não foi observado nos escolares com o mesmo quadro. Tal fator, segundo os autores, pode estar associado ao fato de que a intervenção terapêutica é capaz de oferecer resultados mais expressivos para os aspectos da forma do que para os pragmáticos.

Outra análise, realizada também na segunda investigação, utilizou o Preschool Behaviour Questionnaire (PBQ) para verificar o impacto das características comportamentais associadas ao TDAH no perfil linguístico dos pré-escolares com DEL e DEA. Os resultados mostram que a impulsividade, característica das crianças com TDAH, parece afetar tanto a 
estrutura linguística quanto a pragmática, o que não ocorre para a falta de atenção e hiperatividade, também características das crianças com TDAH. O aumento na presença de características impulsivas nas crianças com DEA e DEL esteve associado ao aumento nas dificuldades linguísticas.

Nota-se ainda, pelos resultados apresentados, que a percepção dos pais e seus relatos acerca da comunicação dos filhos com DEA se modificam ao longo do tempo, fato que alerta para a importância de se considerar qual a prioridade familiar ao ser determinado o foco do processo terapêutico. É interessante atentar para as habilidades de linguagem ao avaliar crianças com TDAH, mas também é importante verificar a presença das características clássicas do TDAH em crianças com déficits da comunicação, pois a impulsividade se mostra como um indício de dificuldades linguísticas.

Os autores do artigo sugerem que o CCC- 2 corresponde a uma medida válida para diferenciar as crianças com desordens que acometem o desenvolvimento da linguagem daquelas em desenvolvimento típico, podendo ser utilizado como instrumento de triagem.

Mesmo que o artigo que estamos analisando tenha sido publicado em 2008, não sendo então tão novo, apresenta a nova versão do CCC, agora revista, da qual os fonoaudiólogos brasileiros que trabalham com linguagem infantil devem se interar. Além disso, vale aqui refletir sobre as proposições apresentadas pelos autores. Inicialmente cabe destacar que o CCC, seja na primeira ou na segunda versão, é um checklist, cuja análise deriva de informações fornecidas por pais/cuidadores, então, mesmo sendo um instrumento validado internacionalmente e considerado como fidedigno, deve ter seus resultados analisados especificamente como uma triagem quando se trata da realização de diagnóstico em linguagem.

Obviamente, quadros como os estudados no presente artigo, diferem entre si pela própria sintomatologia e sua diferenciação deve ocorrer para análise linguística, que pode trazer importantes subsídios para diagnósticos diferenciais e esclarecimentos de conduta em reabilitação. Informações importantes foram fornecidas, a partir dos resultados obtidos no estudo no que se refere às mudanças das observações dos pais/cuidadores sobre das crianças com DEA pré-escolares e escolares, à heterogeneidade das manifestações linguísticas dos DEL, à questão das associações entre presença de impulsividade, característica do TDAH, e as manifestações linguísticas das crianças com DEL e DEA.

Entretanto, o principal aspecto de reflexão é o que não está formalizado no texto apresentado, mas sugerido. As confirmações das informações que clinicamente devem-se obter podem ser apoiadas em um checklist, mas obrigatoriamente devem ser confirmadas por uma avaliação consistente de linguagem, que analise cada subsistema (fonético/fonológico, semântico, morfossintático e pragmático) separadamente e em funcionamento para que se possa garantir com a máxima precisão possível as manifestações de linguagem apresentadas pela criança em avaliação. 